\title{
Plant Insurance
}

\section{By Keith Best and Archie Budd-Swift Current}

Many of the weedy plants appear to possess an almost uncanny faculty for self preservation. "How is it," many folk ask, "that after a season of good clean fallow, the crcp contains many newly germinating weeds, even after a good germination of weeds during the fallow year?" Some plants bear two kinds of seed on the same plant, one kind germinating during the first growing season, the other kind having a long-delayed germination period. In at least four species the two kinds can be deitermined by observation. These are Garden Atriplex, Orache, Russian Pigweed and Cocklebur. The first three belong to the Goosefoot family and the fourth is allied to the Ragweeds.

Garden Atriplex or Copper Orache (Atriplex hortensis) is a garden plant which is becoming an annoying weed around urban areas. The ornamental strain has reddish leaves but after self seeding it reverts to its original green-leaved strain. This plant bears large panicles of fruit, looking very like stinkweed with a tall, three to four foct stem and broad leaves. Close inspection will show that on the same plant are two quite different kinds of seed, the most abundant being large, pale brown, flat about $1 / 8$ inch in diameter and enclosed in a pair of pale brown bracts. The other kind are small, black and shiny, about $1 / 12$ inch across and not enclosed in bracts. The large, bracted kind will germinate after sowing in spring in a very few days, but the bractless, black seeds will not germinate until at least the following spring and sometimes even later.

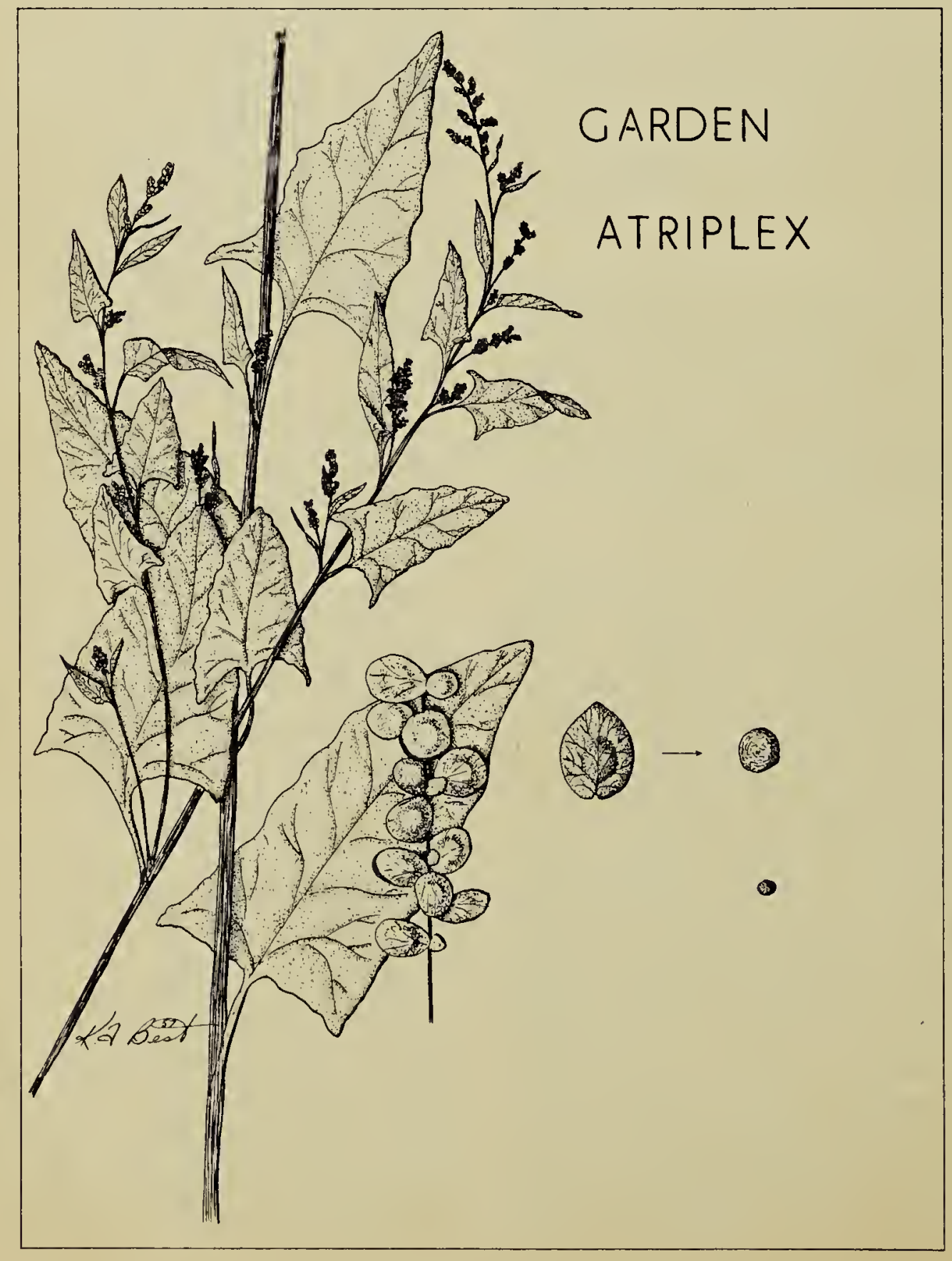


Russian Pigweed (Axyris amaranthoides) is a common weed of gardens and shelter belts and produces copious quantities of seed. These also are of two different kinds in the same inflorescence. One kind bear the two-lobed membranous ears at the wider end and seem to be somewhat blotched and long oval in shape. The other kind are almost round, silvery in colour and bear no membranous ears. The eared variety germinate very early in spring but the other, non-eared kind, delay germination at least one season, perhaps more.

In Orache (Atriplex patula) a similar variation of seed occurs, but in this case one kind is larger than the other, the larger having the early germination and the smaller the delayed.

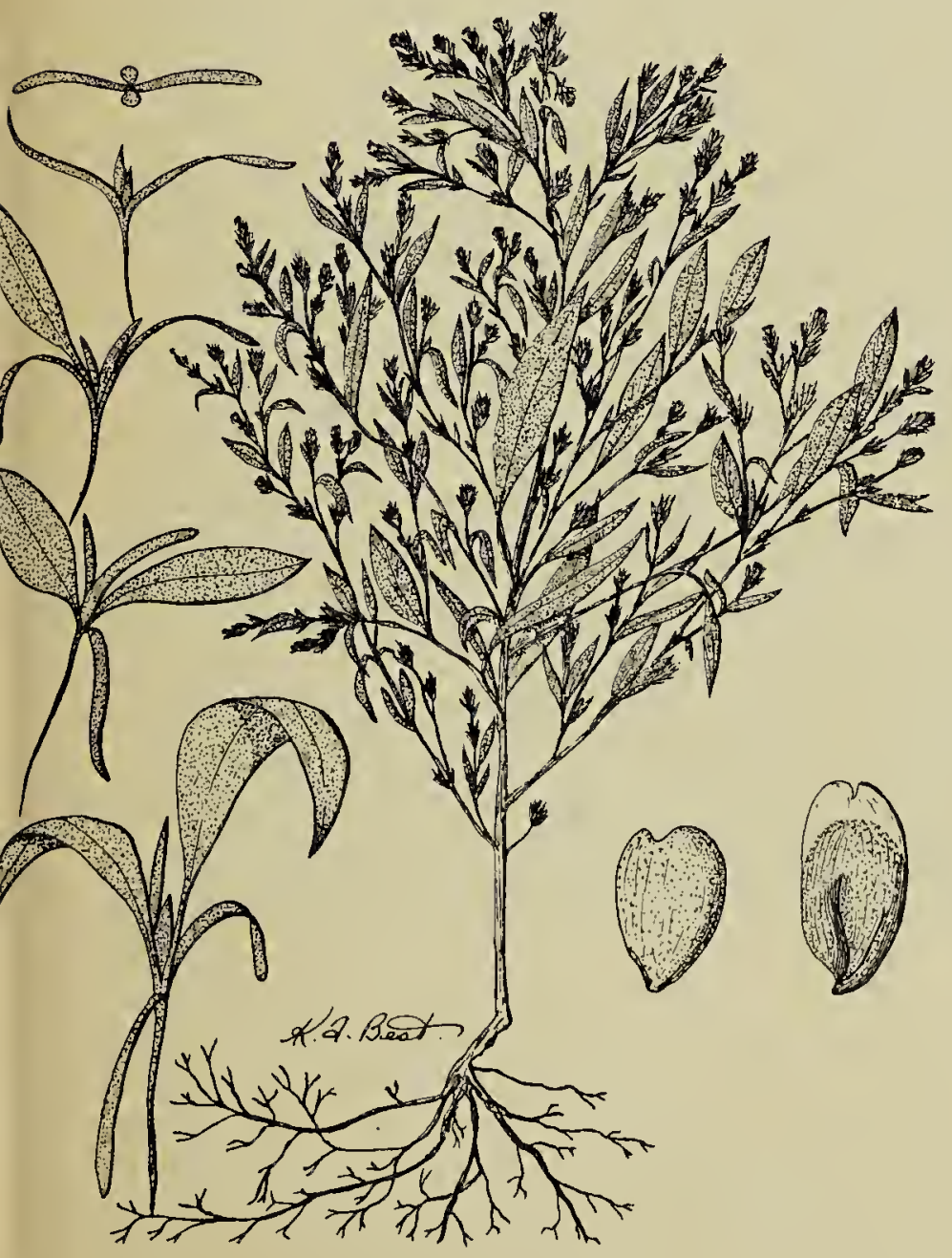

RUSSIAN PIGWEED
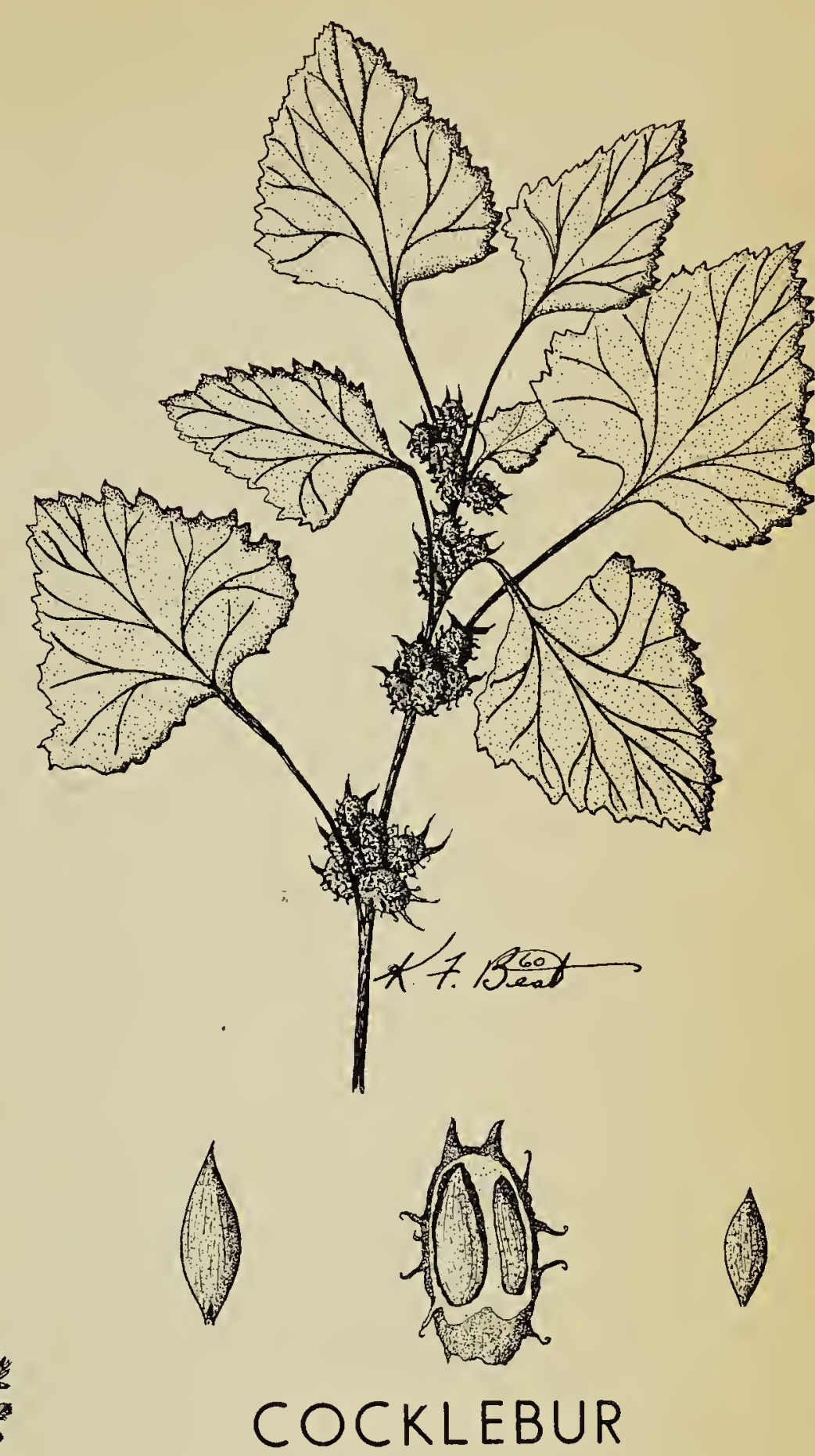

Cocklebur (Xanthium spp.) bears prickly burs each containing two long, narrow black seeds, one considerably larger than the other. Studies made at Swift Current show that the larger seed will grow the first season after seeding but that the smaller one delays its germination at least one season.

It is quite possible, in fact probable, that many plants similarly bear two kinds of seeds and act in the same manner regarding their delayed germination. More studies along this line may bring to light some interesting facts and help suggest means to combat some of our nuisance plants. 